2018 Modular and Offsite Construction (MOC) Summit

@

World of Modular, March 22-25

The Diplomat Beach Resort, Hollywood, FL, USA

\title{
Construction Capacity and New Housing Demand Caused by Tornados
}

\author{
Augusto ALVES ${ }^{1 *}$ and David ARDITI ${ }^{2}$ \\ ${ }^{1}$ PhD candidate, Department of Civil Engineering, Illinois Institute of Technology \\ ${ }^{2}$ Professor, Department of Civil Engineering, Illinois Institute of Technology \\ *Corresponding author's e-mail: augustoac@yahoo.com,aalvesde@hawk.iit.edu
}

\begin{abstract}
Recent research shows that construction of new houses takes the majority of the recovery time after a tornado. The rapid procurement of new houses depends largely on the existing construction capacity in the region affected. In this study, information about the construction industry in a tornado-prone region is extracted from U.S. economic Census data by using NAICS (North American Industry Classification System) categories. The present capacity of the construction industry is calculated by extracting (1) the inventories of materials and supplies, and (2) the value of new houses put in place in a targeted tornado-prone region, in this study, Oklahoma. A method is proposed to calculate the extra construction capacity in the targeted region using the information extracted from U.S. Census data. The extra construction capacity hence calculated is then compared to the anticipated need for new houses after a severe tornado, calculated by considering the historical records of damages caused by past tornados. The results of the study indicate that the existing construction capacity in the Oklahoma region is not enough to rapidly respond to the anticipated need for new houses after a tornado.
\end{abstract}

\section{KEYWORDS}

Tornado prone region; Oklahoma tornado damage; Modular and offsite construction capacity; Housing construction industry; Census data economic analysis, offer and demand study

\section{INTRODUCTION}

Many researchers have reported that disasters are expanding in scale and in occurrence. Today humanity occupies more land than forty years ago. Statistically, present communities are prone to higher chances of being affected by disasters. Consequently, this number will grow. Disasters cause loss of life and damage to property. "Between 1994 and 2013, EM-DAT \{http://www.emdat.be/\} recorded 6,873 natural disasters worldwide, which claimed 1.35 million lives or almost 68,000 lives on average each year. In addition, 218 million people were affected by natural disasters on average per annum during this 20-year period" (CRED 2015). 
Most communities respond after a disaster strikes by putting in time, resources, money, and effort to reconstruct destroyed property and to repair damaged property. The existing construction capacity in the region affected may significantly impact the procurement of new houses.

Tornados occur frequently in the U.S. and cause substantial loss of life and damage to property. A tornado occurs typically in the period from late March to mid-June every year. One destructive tornado (Category 5) comes approximately every 7.6 years (Doswell et al. 2012). Brooks and Doswell (2001) estimated the damage caused by tornados to be $\$ 19.3$ billion in the U.S. in the 46year period from 1950 to 1995 , i.e., an average of $\$ 420$ million in damages per year, normalized for inflation.

In the 136 years from 1875 to 2011 there have been 18 tornados with more than 300 fatalities each. From 1890 to 1999 , 6,572 lives were taken by tornados, which translates to 60.3 lives per year (Brooks and Doswell 2001). Brown et al. (2002) explain that the death rate was estimated to be more than one person per 10 units in mobile homes, while the death rate was estimated less than one person per 200 units in permanent homes in the Oklahoma City tornado. Thus, the risk to mobile home residents was at least 20 times as great as the risk to permanent home residents in Oklahoma City.

The building construction industry has to respond to spikes in housing demand when tornados strike. In this study, information about the present capacity of the construction industry in a tornado-prone region is extracted from U.S. economic Census data. The mathematical model rely on the assumption of a comparison between existent material in stock for construction and actual construction in place. The construction capacity hence calculated is compared to the anticipated need for new houses after a severe tornado. The objective is to see if the construction capacity is able to meet demand for new houses caused by destructive tornados.

After this explanation about why this research was undertaken, the paper proposes a model to calculate the capacity of the construction industry in a particular region. It then presents and discusses the results of a study that uses the proposed model with data collected from the Census. The results of the study are expected to help plan for more effective reconstruction efforts after a tornado hits.

\section{PROPOSED MODEL}

The basic assumption in this study is that the inventory of supplies and materials in a given region affects the readiness for recovery after a disaster. The proposed model is limited to the construction of new houses after a tornado, and does not cover repair or renovation of partially damaged structures. Neither does it cover other natural disasters such as earthquakes and floods. The model relies on U.S. economic Census data.

The geographical region under study is divided into multiple zones based on the intensity and frequency of tornado events. Figure 1 shows the Red Cross (2011) chart of the risk areas for tornados, including the states of IL, TX, OK, KS, NE, IA, MO, AR, LA, MS, AL, TN, KY, IN. 
This study focuses on understanding the concept of construction capacity. It explores the construction capacity in the residential market of tornado-prone areas. The extra capacity of residential construction $\left(\mathrm{C}_{\mathrm{rx}}\right)$ that can be built with the available inventory of materials and supplies is calculated by using Equations 1 and 2.

$\frac{M \& S_{i n v} *\left(\frac{\mathrm{C}_{r}}{\boldsymbol{C}_{a l l}}\right) * \boldsymbol{f}}{\boldsymbol{C}_{r x}}=\frac{M \& \boldsymbol{S}_{r}}{C_{r}}$

$C_{r x}=\frac{M \& S_{i n v} * C_{r}^{2} * f}{M \& S_{r} * C_{a l l}}$

where

$M \& S_{\text {inv }}=$ Total value of inventory over the year in designated region

$M \& S_{r}=$ Expenditure in residential materials and supplies in designated region

$\mathrm{C}_{\mathrm{r}}=$ Value of residential construction in designated region

$\mathrm{C}_{\text {all }}=$ Value of all construction in designated region

$\mathrm{C}_{\mathrm{rx}}=$ Extra capacity of residential construction in designated region

$f \quad=$ Percentage of the value of new housing in total construction (total construction includes renovation, repair, rehabilitation, and new construction)
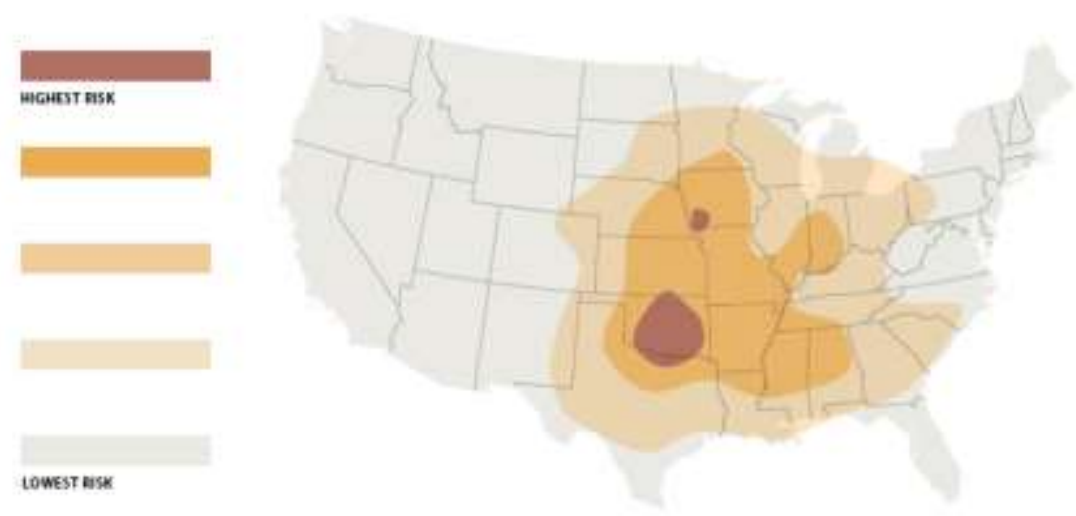

Figure 1. Red Cross map of tornado prone regions in the U.S.

The following NAICS (North American Industry Classification System) categories are used to collect the data for the calculation of the construction capacity in tornado-prone regions (CENSUS 2017, NAICS 2017):

(1) NAICS Codes \#4233, \#423610, \#4237 - These three codes are listed under the Wholesalers Durable goods (\#423). The three categories are: Lumber and other 
construction materials merchant wholesalers (\#4233); Electrical apparatus and equipment, wiring supplies, and related equipment merchant wholesalers - (\#423610); and Hardware and plumbing and heating equipment and supplies merchant wholesalers (\#4237). This data is used to calculate Material and Supplies Inventory, M\&S $\mathrm{S}_{\text {inv. }}$ "Total inventories at the beginning and end of the year" are considered in these calculations.

NAICS Code \#23 - Construction whole industry economic revenue in 2012, including non-residential building construction and infrastructure. This data is used to calculate $\mathrm{C}_{\text {all. }}$. The "Value of sales, shipments, receipts, revenue, or business done" is considered in these calculations.

(3) NAICS Codes \#236115, \#236116, \#236117 and \#236118 - These four codes are listed under the Residential Building Construction category (\#2361) and represent (a) new single-family housing construction (except for-sale builders) (\#236115); (b) new multifamily housing construction (except for-sale builders) (\#236116); (c) new housing (for-sale builders) (\#236117); and (d) residential remodelers (\#236118). This data is used to calculate $C_{r}$ and $M \& S_{r}$. The "Cost of materials and supplies" is considered in calculating $M \& S_{r}$. The "Value of sales, shipments, receipts, revenue, or business done" is considered in calculating $\mathrm{C}_{\mathrm{r}}$.

The inventory of materials and supplies $\left(M \& S_{\text {inv }}\right)$ represents the wholesale value of extra material and supply in stock, after local demand has been met. This extra inventory can be used in case of a peak in the demand. How many houses can be built after a tornado, using this extra inventory? The rationale used in developing Equations 1 and 2 is explained in detail in the following paragraphs.

First, to find the amount of the inventory that is destined to residential construction and renovation, the average inventory $\left(M \& S_{\text {inv }}\right)$ is multiplied by the ratio of residential construction $\left(\mathrm{C}_{\mathrm{r}}\right)$ to the value of all construction $\left(\mathrm{C}_{\text {all }}\right)$ put in place. Then, the amount of the inventory that is destined to the construction of only new houses (no renovation) is calculated by multiplying this value by a factor $(f)$ that represents the percentage of new houses put in place, as opposed to renovation. In this study $f=15 \%$, while the remaining $85 \%$ represent renovation and restauration of damaged houses not totally destroyed by the tornado. The coefficient $(f)$ was taken as $15 \%$ because the Joplin, MO tornado had 7,191 homes affected, with 1,042 considered destroyed, resulting in a $14.49 \%$ rate of destruction as described by Marshall et al. (2012) through a damage survey.

The numerator of the expression on the left of the equal sign in Equation 1 is thus the value of materials and supplies that can be used to replace totally destroyed houses after a tornado. The denominator is the value of new housing $\left(\mathrm{C}_{\mathrm{rx}}\right)$ that can be built with this inventory.

The right hand side of the equality represents how much materials and supplies $\left(M \& S_{r}\right)$ are used to put in place new houses $\left(\mathrm{C}_{\mathrm{r}}\right)$ in designated regions. $\mathrm{C}_{\mathrm{rx}}$ represents the only unknown variable in Equation 1 and determines the value of new houses that can be built using the extra inventory. Equation 2 is an expression that lets one to calculate $\left(\mathrm{C}_{\mathrm{rx}}\right)$. 


\section{RESULTS AND DISCUSSION}

The information obtained from the Census website following the NAICS codes described earlier is used to calculate $\mathrm{C}_{\mathrm{rx}}$ in Equation 2. The results for the different tornado-prone regions are presented in Table 1.

As an example, looking at Oklahoma State, the construction industry in the State of Oklahoma can build 90 houses if a tornado hits. If a tornado destroys more than 90 houses, the construction industry is not able to meet the demand with the existing inventory of materials and supplies. It is also known that the maximum number of 90 houses that can be built in Oklahoma after a serious tornado, if built fast, will take at least two years to complete. It should be possible to rebuild destroyed houses much faster than that, greatly improving the recovery time of a region.

Table 1. Extra capacity for residential construction

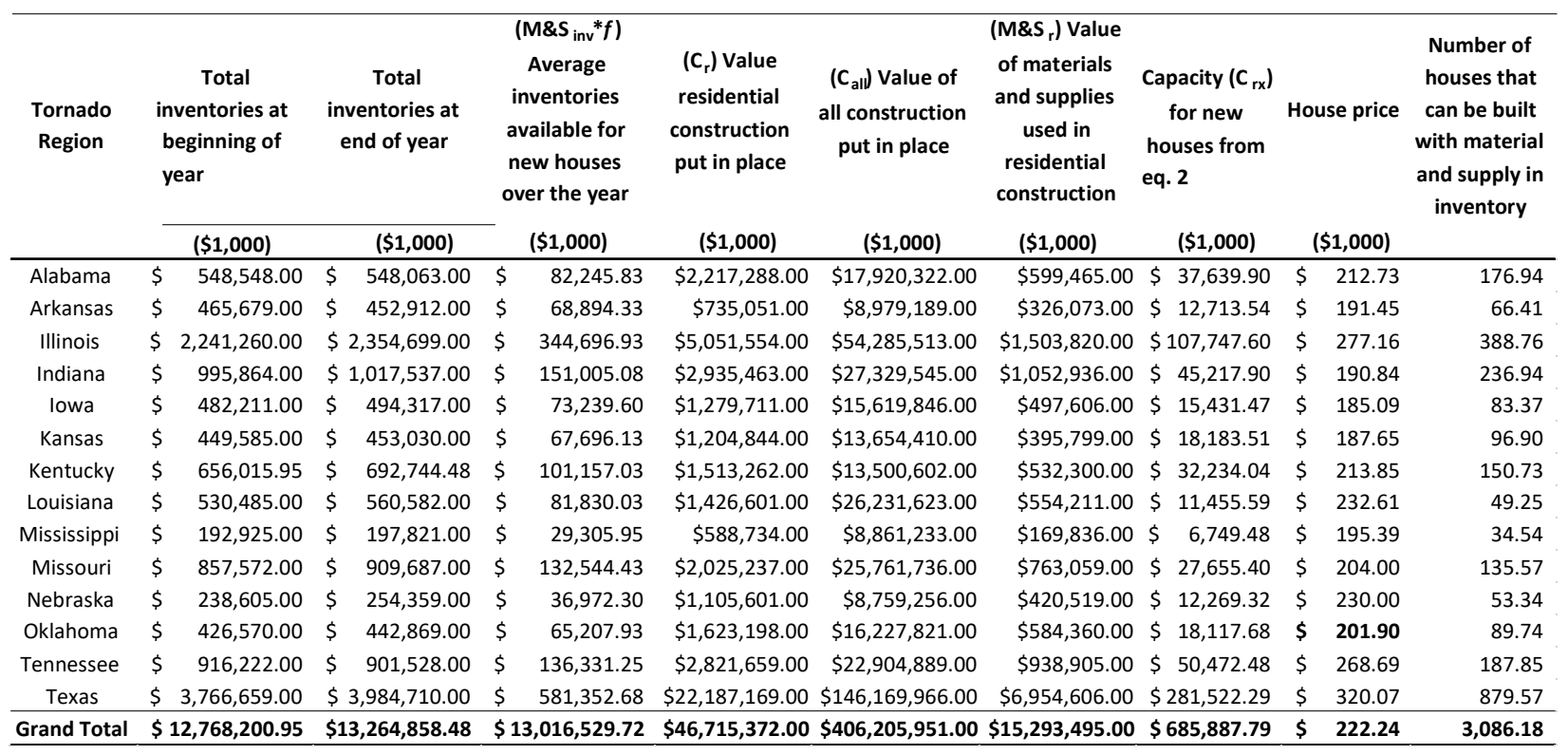

As far as demand for new houses caused by severe tornados is concerned, the 1999 and 2013 tornados EF5 in Oklahoma City, caused \$1 billion and \$2 billion in damages, respectively. Following the report of FEMA and the Oklahoma Emergency Management Agency (1999), 3,133 homes were destroyed, accounting for approximately \$221.5 million in damages in 1999 . Considering today's median home value of $\$ 202,000$ per house in Oklahoma, this demand could not have been met with the inventory of materials and supply at hand today.

According to the National Weather Service (2017), tornado damage in Oklahoma City in the last 25 years $(1991$ - 2016) was $\$ 3.4174$ billion, amounting to $\$ 136.698$ million in damage per year on average. Assuming that only $15 \%$ of the average damage is caused by completely destroyed houses:

$$
\begin{aligned}
\text { Value of destroyed houses per year } & =\$ 136.698 \times 10^{6} \times 0.15 \\
& =\$ 20,504,000 \text { per year }
\end{aligned}
$$


Considering that a standard house costs $\$ 202,000$ in Oklahoma State, one can calculate the average number houses destroyed by tornados in Oklahoma:

$$
\begin{aligned}
\text { Number houses destroyed by tornados } & =\$ 20,504,000 / \$ 202,000 \text { per house } \\
& =101 \text { houses per year }
\end{aligned}
$$

The number of houses destroyed in Oklahoma City (average demand: 101 houses per year) is larger than the number of houses that can be built with the existing inventory of materials and supplies (average supply: 90 houses per year as of the information in Table 1) in the State of Oklahoma.

According to this information, the extra construction capacity of 90 homes per year in the State of Oklahoma is not able to meet not only the peak demand caused by a very severe tornado such as the one reported by FEMA and the Oklahoma Emergency Management Agency that resulted in the destruction of 3,133 homes in 1999, but also the average demand for 101 new homes caused by tornados every year.

One should also consider that tornados are becoming more numerous. Over the last 50 years, the number of tornados reported in the U.S. has doubled from 600 per year in the 1950's to around 1,200 in the 2000's (Verbout et al. 2006). As shown in Figure 2, according to Ashley et al. (2014), the expanding "bull's eye effect" in metropolitan areas, growing population, and territorial occupancy explain the increasing trend in tornado damage over the years.
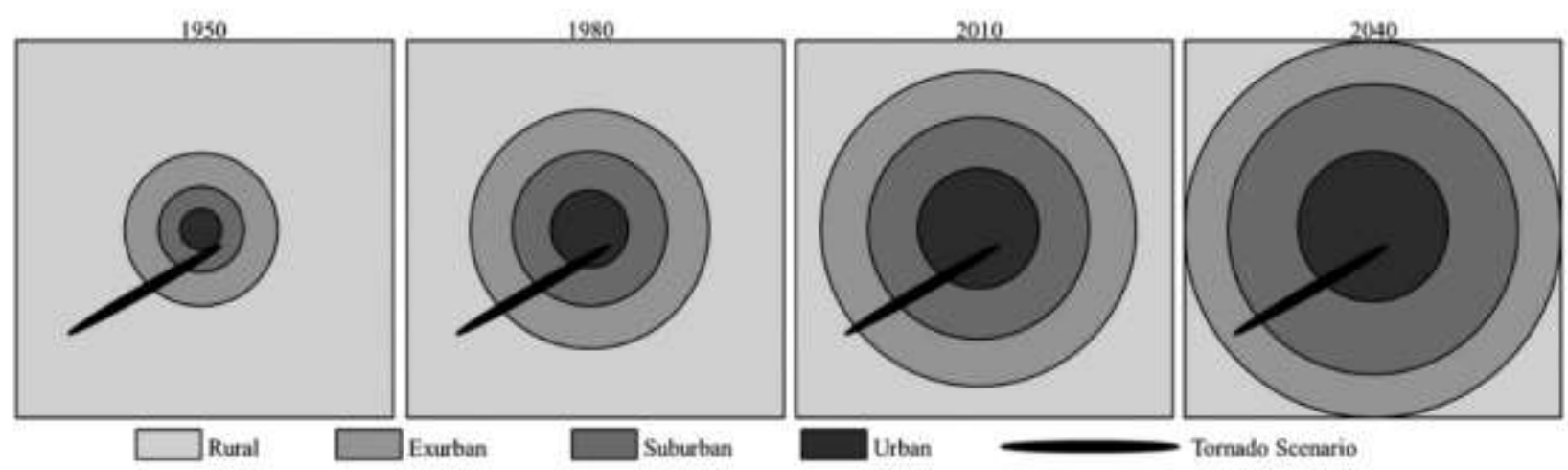

Figure 2. "Bull's eye effect" augmenting impact over time (Ashley et al. 2014)

\section{CONCLUSION}

In this paper, a model to measure the construction capacity in a region using U.S. economic Census data that is readily available to the public of a tornado region was proposed and calculated. A comparison between demand for new homes caused by tornados and the construction capacity in that tornado region is expected to better explain the degree of preparedness in that region.

Special attention was given to Oklahoma State in this study because approximately $10 \%$ of all tornados in the U.S. occur in this state. It was found that the extra inventory of construction 
materials and supplies in Oklahoma State is not able to meet peak or average demand for new houses caused by destructive tornados. It is likely that the situation is not any different in other tornado-prone regions. It is clear that the construction industry's capacity needs to be radically improved for effective recovery efforts after a tornado. This can take the form of a larger inventory of materials and supplies or of different construction methods such as modular houses.

This study is confined to tornados, and excludes other disasters such as earthquakes, hurricanes, landslides, and floods. This limitation can be overcome by undertaking studies in the future to develop variations of the model proposed in this paper. A second limitation of this study is that a conservative approach was taken in selecting the data used in populating the model. An approach can be used in future research that extrapolates the demand for new homes based on the "bull's eye effect" and that factors in the probability of experiencing more destructive tornados than those of 1999 and 2013 in Oklahoma State.

The findings of the proposed research are expected to positively affect policy-making in the construction industry. The research findings shed light not only on an inadequate construction capacity in tornado-prone regions, but they also point out that construction speed and construction methods may need to be improved in order to meet the needs of the tornado-stricken population. The currently accepted norm that recovery after a tornado takes at least two years needs to be challenged. The building construction industry has to be able to respond to spikes in demand for new homes when tornados strike.

\section{ACKNOWLEDGEMENTS}

The authors would like to thank the Brazilian CAPES "Coordenação de Aperfeiçoamento de Pessoal de Nível Superior" program administered by LASPAU, for their greatly appreciated support.

\section{REFERENCES}

Ashley, W. S., Strader, S., Rosencrantz, T., and Krmenec, A. J. (2014). "Spatiotemporal changes in tornado hazard exposure: the case of the expanding bull's-eye effect in Chicago, Illinois." Weather, Climate, and Society, 6(2), 175-193.

Brooks, H. E., and Doswell, C. a. (2001). "Normalized Damage from Major Tornadoes in the United States: 1890-1999." Weather and Forecasting, 16 (FEBRUARY 2001), 168-176.

Brooks, H. E., and Doswell III, C. A. (2002). "Deaths in the 3 May 1999 Oklahoma City tornado from a historical perspective." Weather and Forecasting, 17(3), 354-361.

Brown, S., Archer, P., Kruger, E., and Mallonee, S. (2002). "Tornado-related deaths and injuries in Oklahoma due to the 3 May 1999 tornadoes." Weather and Forecasting, 17(3), 343-353.

CENSUS, Gov. (2017). "American FactFinder” United States Census Bureau, Dept of Commerce, $<$ https://factfinder.census.gov> (Aug. 20, 2017).

CRED. (2015). "The Human Cost of Natural Disasters 2015: Global Perspective."

Doswell, C. A., Carbin, G. W., and Brooks, H. E. (2012). "The tornadoes of spring 2011 in the USA: An historical perspective." Weather, 67(April 1974), 88-94.

NAICS. (2017). "North American Industry Classification System." 
National Weather Service (2017). "Table of Tornadoes Which Have Occurred in the Oklahoma City" < https://www.weather.gov/oun/tornadodata-okc-table > (Oct. 30, 2017).

Oklahoma Emergency Management Agency, OEMA (1999). "May 3-5 tornadoes, severe storms and flooding", congressional briefing, 7 July. Oklahoma City.

Red Cross (2011). "Transitional Shelters Eight designs." 1-96.

Speheger, D. A., Doswell III, C. A., and Stumpf, G. J. (2002). "The tornadoes of 3 May 1999: Event verification in central Oklahoma and related issues." Weather and forecasting, 17(3), 362-381.

Smith, D. J., and Sutter, D. (2013). "Response and Recovery after the Joplin Tornado: Lessons Applied and Lessons Learned." Independent Review, 18(5), 165-188.

Verbout, S. M., Brooks, H. E., Leslie, L. M., and Schultz, D. M. (2006). "Evolution of the US tornado database: 1954-2003." Weather and Forecasting, 21(1), 86-93. 